\title{
Peroral cholangioscopy of programmed cell death-1 inhibitor-related sclerosing cholangitis: three case reports
}

Programmed cell death-1 (PD-1) inhibitor therapy is indicated for many types of malignancies, but can lead to immune-related adverse events [1,2]. Recently, PD-1 inhibitor-related cholangitis and its clinical features, including peroral cholangioscopy, were reported [3-5]. However, the diagnostic criteria of PD-1 inhibitor-related cholangitis are unclear. We herein report peroral cholangiography for three patients with suspected pembrolizumab-related sclerosing cholangitis.

Case \#1 was a 61-year-old man with bladder cancer who had been treated with pembrolizumab as third-line chemotherapy. After his fifth course of pembrolizumab, he was admitted to our hospital complaining of pyrexia. Case \#2 was an 89-year-old man with bladder cancer. After his fourth course of pembrolizumab as second-line chemotherapy, he was admitted to our hospital for examination of liver dysfunction. Case \#3 was a 63-year-old man with lung cancer. After his seventh course of pembrolizumab as first-line chemotherapy, he was admitted to our hospital because of liver dysfunction.

Laboratory data from all three patients revealed increased liver and biliary enzymes. Computed tomography and endoscopic ultrasonography consistently showed diffuse symmetric wall thickening of extrahepatic bile ducts without any obstruction ( $\mathbf{F i g} \mathbf{1} \mathbf{1} \mathbf{a}, \mathbf{b}$ ). Endoscopic retrograde cholangiopancreatography revealed an irregular bile duct wall in all three patients ( $\boldsymbol{F i g . 1} \mathbf{c}$ ). Peroral cholangioscopy revealed band-like narrowing of the wall of the biliary tract in all three patients and diverticulumlike outpouching in patients \#1 and \#3 ( $\vee$ Fig. $1 \mathrm{~d}$; $\triangleright$ Video 1 ).
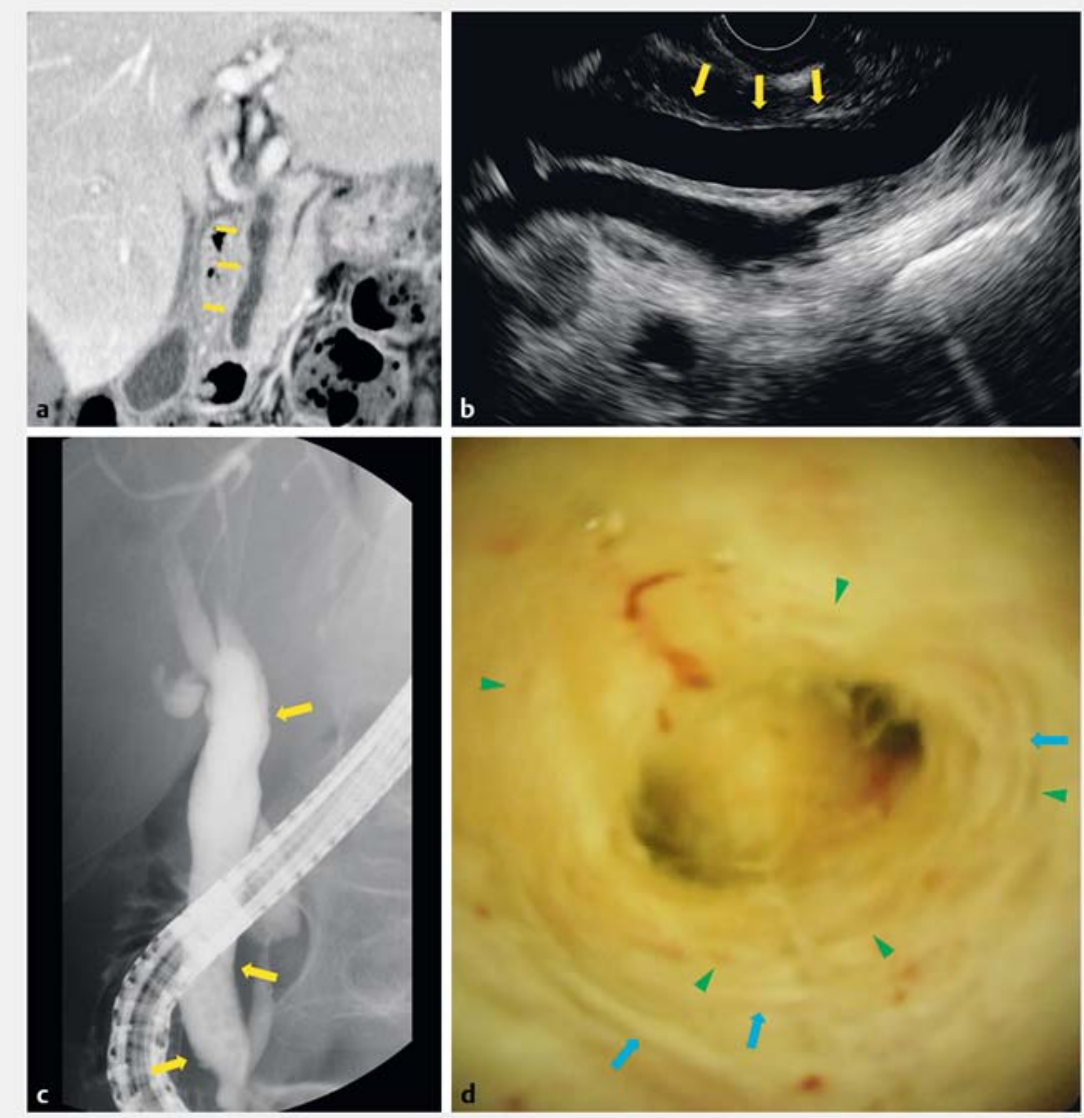

- Fig. 1 Images from patient \#3, a 63-year-old man receiving pembrolizumab for lung cancer. a Computed tomography image showing diffuse wall thickening (arrows) of the extrahepatic bile duct, but no obstruction or stenosis in the distal bile duct. b Endoscopic ultrasonography image showing diffuse wall thickening of extrahepatic bile duct (arrows). c Endoscopic retrograde cholangiopancreatography image showing an irregular bile duct wall (arrows). $\mathbf{d}$ Peroral cholangioscopy image showing areas of band-like narrowing of the wall of the biliary tract (arrows) and a diverticulum-like outpouching (arrowheads).

A biopsy of the lesions of the extrahepatic bile duct showed inflammatory cells in the bile duct epithelium ( $>$ Fig. 2). All patients received internal treatment with ursodeoxycholic acid. Patient \#1 was also treated with oral prednisolone. Liver and biliary enzymes improved gra- dually in all three patients, although normalization of enzyme activities was not achieved.

Endoscopy_UCTN_Code_CCL_1AZ_2A] 


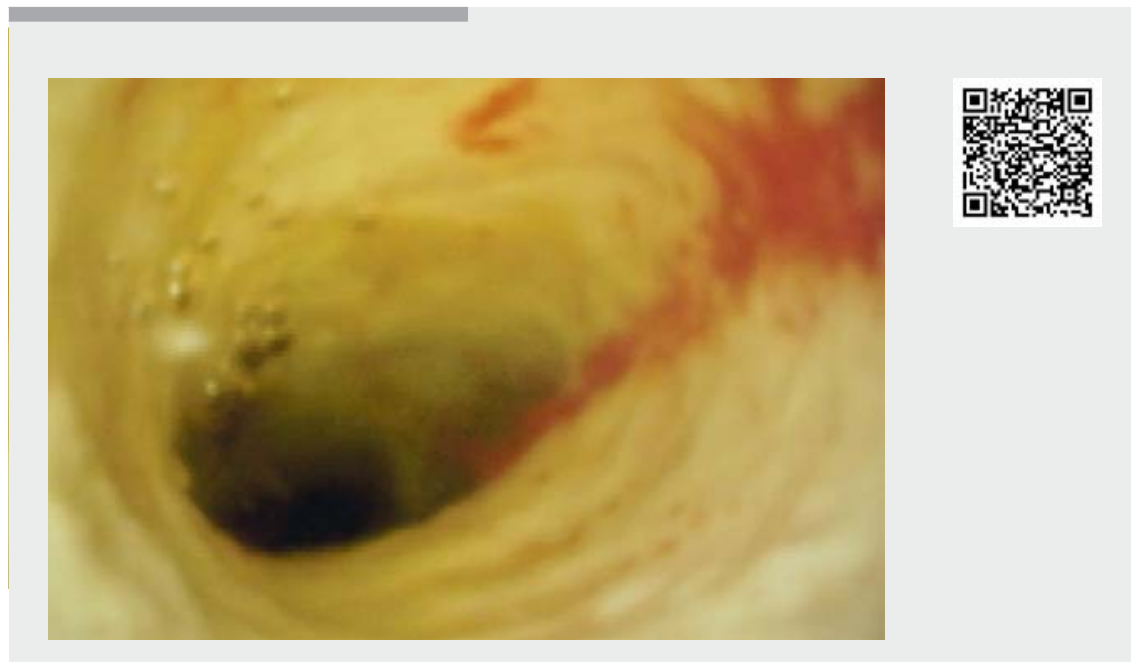

Video 1 Peroral cholangioscopy showing multiple areas of band-like narrowing of the wall of the biliary tract, which was present in all patients, and a diverticulum-like outpouching, which was present in patients \#1 and \#3.

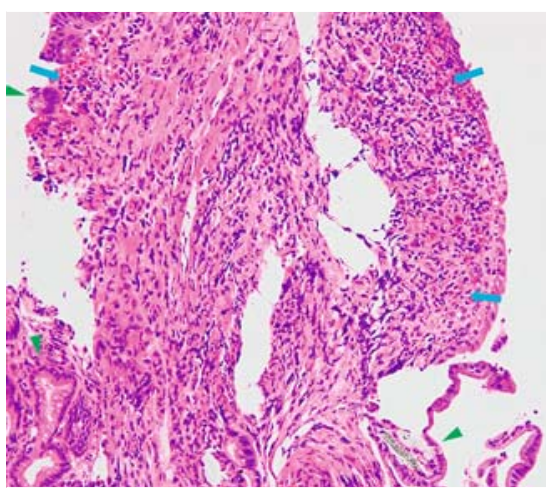

- Fig. 2 Histopathological appearance showing an infiltration of inflammatory cells (arrows), including neutrophils and lymphocytes, in the epithelium of the extrahepatic bile duct (arrowheads).

\section{Competing interests}

None

The authors

Takumi Onoyama, Yohei Takeda, Masayuki Kato, Mirai Edano, Ryohei Tarumoto, Kazuya Matsumoto, Hajime Isomoto

Division of Medicine and Clinical Science, Department of Multidisciplinary Internal Medicine, Tottori University, Yonago, Japan

\section{Corresponding author}

\section{Takumi Onoyama, MD, PhD}

Division of Medicine and Clinical Science, Department of Multidisciplinary Internal Medicine, Faculty of Medicine, Tottori University, 36-1 Nishi-cho, Yonago 6838504 , Japan

golf4to@yahoo.co.jp

[1] Villadolid ], Amin A. Immune checkpoint inhibitors in clinical practice: update on management of immune-related toxicities. Transl Lung Cancer Res 2015; 4: 560 - 575

[2] Spain L, Diem S, Larkin J. Management of toxicities of immune checkpoint inhibitors. Cancer Treat Rev 2016; 44: $51-60$

[3] Kawakami H, Tanizaki ], Tanaka K et al. Imaging and clinicopathological features of nivolumab-related cholangitis in patients with non-small cell lung cancer. Invest New Drugs 2017; 35: 529-536

[4] Gelsomino F, Vitale G, Ardizzoni A. A case of nivolumab-related cholangitis and literature review: how to look for the right tools for a correct diagnosis of this rare immune-related adverse event. Invest New Drugs 2018; 36: $144-146$

[5] Kuraoka N, Hara K, Terai S et al. Peroral cholangioscopy of nivolumab-related (induced) ulcerative cholangitis in a patient with non-small cell lung cancer. Endoscopy 2018; 50: E259-E261

\section{Bibliography}

DOI https://doi.org/10.1055/a-0948-1271

Published online: 24.7.2019

Endoscopy 2019; 51: E402-E403

(c) Georg Thieme Verlag KG

Stuttgart · New York

ISSN 0013-726X

\section{ENDOSCOPY E-VIDEOS}

https://eref.thieme.de/e-videos

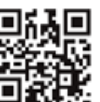

Endoscopy E-Videos is a free access online section, reporting on interesting cases and new techniques in gastroenterological endoscopy. All papers include a high quality video and all contributions are freely accessible online.

This section has its own submission website at

https://mc.manuscriptcentral.com/e-videos 